\title{
Society for Range Management Certified Programs: "Symbol and Substance"
}

\author{
By Leonard Jolley and Jeff Burwell
}

The Society for Range Management (SRM) Denver office receives regular calls and contacts regarding our two certification programs: There is an encouraging and gratifying level of interest and activity in them. Answering repeated questions asking about the differences between the programs, and assisting applicants who were wondering whether one of the programs was for them, led us to write this article for Rangelands.

There appears to be some confusion about the two certification programs that SRM administers. The Certified Range Management Consultant (CRMC) is very different from the Certified Professional in Rangeland Management (CPRM). Let us explain the definition and purpose of each program to clear up any misconceptions.

The CRMC is an individual who generally serves as a paid consultant or who serves with private or nonprofit contractors. The general well being and quality of our rangelands depends on the level of professional competence brought to bear on their use and management. Range consultants are called on to provide a variety of services associated with rangelands and their use. This certification program was established to designate qualified professionals whose standard of consultation is in the best interests of the public and our environment. SRM has 62 CRMCs.

The CPRM is an individual who plans and implements sound management of public and private rangelands and who is generally a person working for a local, state, or federal agency. The overall objective of the program is to provide the means of improving the standards of professional expertise used in managing public and private rangelands. The specific goals of the program are to provide rangeland professionals, government agencies, and the public with minimum education and experience standards and to ensure that practicing rangeland professionals meet such standards; to improve public confidence that our rangeland resources are managed by professionals who pledge to uphold the Code of Ethics and the Standards of Conduct and who act in the best interest of the rangeland resources and the public; and to evaluate professionals through a critical peer-review process based on minimum educational, experience, and ethical requirements. SRM has 532 (and 15 more in process) CPRMs.

Although the purpose of both programs is to benefit the rangeland resources, each program is different and is designed according to the type of rangeland professional who is interested. As of the Kansas City SRM Annual Meeting, new applicants for CRMC must first meet the requirements of a CPRM, including the examination, before proceeding.

The CPRM program of SRM functions both as a symbol and as a thing of substance. Just as the SRM works to strengthen professional standards for activities related to rangeland management, certification is a symbol of this noble effort. Certification is also a symbol of the continuing professional development that characterizes so many of our members, and the certificate on our wall is a further symbol.

There is also substance: the screening of references, work history, and college transcripts are complemented by the need for continuing education and training that we carefully document, both for the benefit of our certified members and to answer any questions that may arise. Newly certified members are also subject to our thorough examination. Those who have obtained a graduate degree in range may feel that the advanced degree is warranty and symbol enough, yet SRM has many certified members with PhDs.

We have used an analogy before, relating our certification to those observed in health care. We rely on and look for certification and registration among the doctors, nurses, and other health professionals we inevitably visit. In this and other realms in which we 
lack expertise, we depend on a reliable and authoritative source to screen and verify the education and experience of a practitioner. Additionally, if called on a witness stand, certification is of great value to establish bona fides.

A certification program diligently created and maintained like ours is reassuring to potential clients. Certification is also a practical way to sift through potential candidates for rangeland planning and management, as the Natural Resources Conservation Service (NRCS) has done by recognizing our certification programs and by considering SRM a "recommending organization." SRM Director Jeff Burwell discussed recently the increasing opportunities for SRM certified members. Of the 1700 Technical Service Providers (TSPs) recognized by US Department of Agriculture NRCS, nearly 90 names were of SRM-certified membersnot too bad given the current dominance of Certified Crop Advisors.

For a profession increasingly in the public eye, certification provides a ready answer to questions

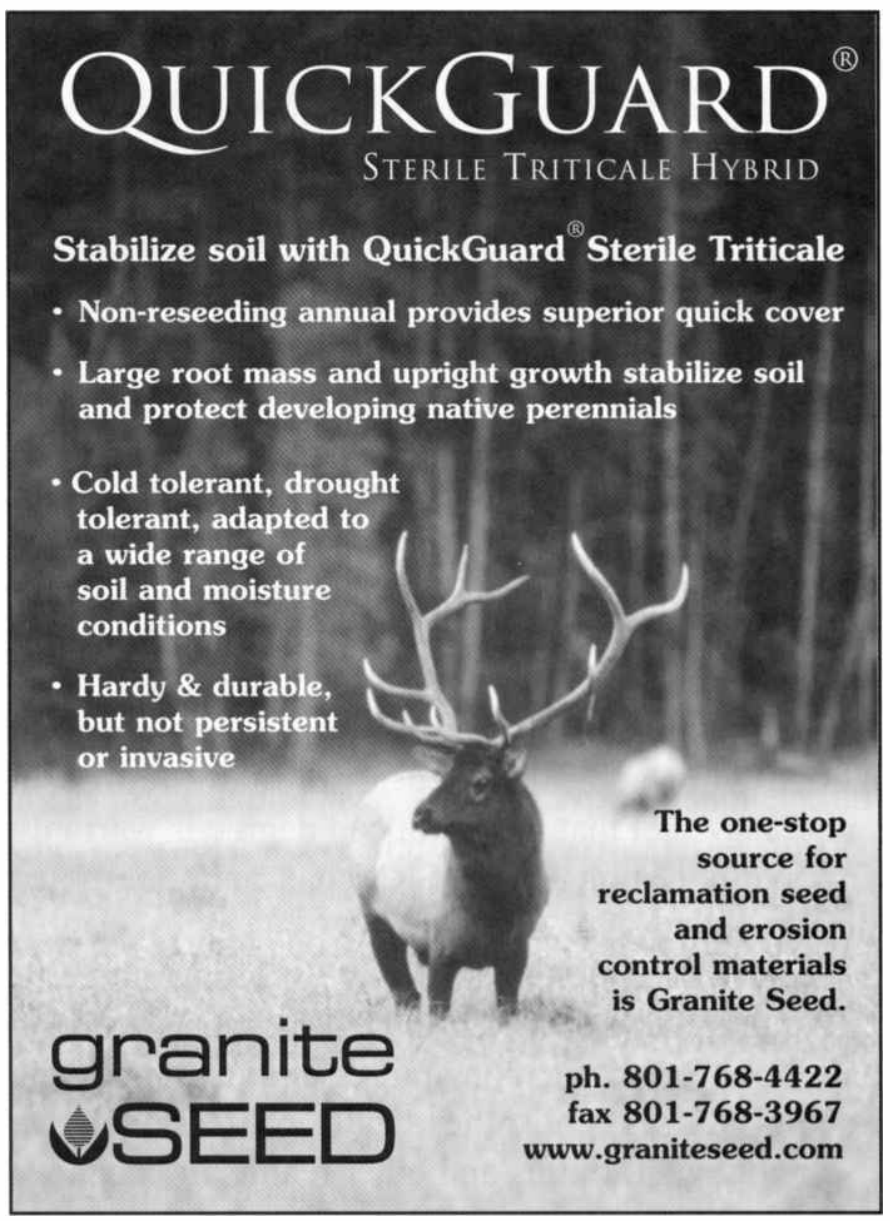

concerning education, experience, and professionalism. Early SRM efforts dealt with distinguishing professional from technician range work. Today, certification has been described as a "gold standard" for a professional society. SRM strives to strengthen professional standards in all range-related venues, and certification is a natural product for us.

The CPRM is a mature program. Because it is more than simply a certificate on the wall, applicants must expect to provide all necessary records of experience, education, and references, along with a modest fee. After earning a passing grade on our thorough exam, applicants may enter the CPRM program, but even then they must document continuing education efforts with our office. We regularly expire CPRMs or put them into a 6-month grace period for inadequate or undocumented continuing education units (CEUs). Your record of CEUs (and other particulars) is always available via our Web site at http://www.rangelands.org. Vicky Skiff has mastered the intricacies of running CPRM details from our iMIS membership database. Our objectives are to maintain the rigor, reputation, and utility of the CPRM program as an important part of SRM's outreach.

Authors are Rangeland Management NRCS Liaison, Society for Range Management, and Director, Society for Range Management, 445 Union Blvd., Suite 230, Lakewood, CO 80228-1259. 